\title{
IDENTIFICAÇÃO DE ÁREAS CRÍTICAS A OCORRÊNCIA DE FOGO NA ÁREA DE ENDEMISMO BELÉM
}

\author{
Gil Mendes Sales \\ Museu Paraense Emílio Goeldi - MPEG \\ Coordenação de Ciências da Terra e Ecologia, Belém, PA, Brasil \\ gilsales@gmail.com \\ Arlete Silva de Almeida \\ Museu Paraense Emílio Goeldi - MPEG \\ Coordenação de Ciências da Terra e Ecologia, Belém, PA, Brasil \\ arlete@museu-goeldi.br \\ Jorge Luis Gavina Pereira \\ Museu Paraense Emílio Goeldi - MPEG \\ Coordenação de Ciências da Terra e Ecologia, Belém, PA, Brasil \\ jorgegavina@museu-goeldi.br \\ Marcelo Cordeiro Thalês \\ Museu Paraense Emílio Goeldi - MPEG \\ Coordenação de Ciências da Terra e Ecologia, Belém, PA, Brasil \\ mcthales@museu-goeldi.br
}

\begin{abstract}
RESUMO
A ação do fogo representa uma importante fatia dos danos gerados aos ecossistemas florestais nas regiões com pressão antrópica. Este estudo teve por objetivo investigar a dimensão espacial e temporal da ação do fogo na Área de Endemismo Belém, nos últimos 20 anos, e avaliar o potencial de vulnerabilidade dos remanescentes florestais desse território, devido pertencer a uma frente de ocupação pioneira antiga e tendo cerca de um terço de sua área coberta com florestas que abrigam espécies endêmicas. Os dados foram trabalhados dentro de um cenário de análise espacial por meio de técnicas de geoprocessamento. Os resultados mostram três zonas de recorrência de fogo como cenários críticos (vulneráveis) aos remanescentes de floresta (Terras Indígenas e Unidades de Conservação, principalmente) de importante biodiversidade. Cerca de $22 \%$ das ocorrências se deram em áreas de Floresta, 18\% em Vegetação Secundária e $29 \%$ em Pasto, representando $70 \%$ dos registros totais em mais de uma década, além da indicação clara da participação das práticas tradicionais de manejo, mesmo com a diminuição do desmatamento. As zonas de maior recorrência dos focos de calor ocorreram em microrregiões com grau de desenvolvimento rural bem abaixo da média nacional, principalmente no quesito preservação ambiental.
\end{abstract}

Palavras-chave: Detecção de Fogo. Remanescentes Florestais. Desenvolvimento Rural. Amazônia Legal.

\section{IDENTIFICATION OF CRITICAL AREAS THE OCCORENCE OF FIRE IN THE BELÉM ENDEMISM AREA}

\begin{abstract}
The action of fire represents an important slice of the damage generated to forest ecosystems in regions with anthropic pressure. This study aimed to investigate the spatial and temporal dimension of fire action in the Belém endemism area, in the last 20 years, and evaluate the potential of vulnerability of the forest remnants of this territory, owing to belong to ancient pioneer occupation front and having about a third of its area covered with forests that harbor endemic species. The data were worked within a spatial analysis scenario through geoprocessing techniques. The results show three zones of fire recurrence as critical (vulnerable) scenarios for forest remnants (Indigenous Lands and Conservation Units, mainly) of important biodiversity. About $22 \%$ of the occurrences occurred in Mature Rainforest, $18 \%$ in Secondary Regrowth
\end{abstract}


and $29 \%$ in Pasture, representing $70 \%$ of the total records in more than a decade, besides the clear indication of the participation of traditional land use practices, even with the reduction of deforestation. The areas of greatest recurrence of heat sources occurred in microregions with a degree of rural development much below from national average, mainly in environmental preservation criteria.

Keywords: Fire Detection. Remaining Forests. Rural Development. Legal Amazon.

\section{INTRODUÇÃO}

Assunto presente nas questões ambientais do planeta, há pelo menos 30 anos, a Amazônia guarda em si uma importante fatia da biodiversidade do planeta e como tal, no consciente coletivo global, é expressada como sendo necessária à preservação e conservação. Entretanto, a permanência em profundidade de questões ambientais emblemáticas e históricas como, por exemplo, o desmatamento e as práticas de queima para fins produtivos, continua em voga e representam uma verdadeira dicotomia no rumo a um desenvolvimento sustentável pleno. Neste sentido, o direcionamento do entendimento para níveis mais amplos perpassa por aspectos mais sinérgicos que não apenas em observar e contabilizar valores de ausência da cobertura vegetal, dado os seus devidos créditos, evidentemente.

Ferreira et al. (2015), destaca que é necessário se considerar, discutir e avaliar o aspecto degradacional da floresta, pois somente o quantitativo da cobertura florestal não deve ser o único indicador da conservação florestal, mas também o conhecimento da integridade ("qualidade") de seus remanescentes florestais.

Uma ameaça crescente às florestas da Amazônia, as queimadas e incêndios representam uma importante forma de degradação do ecossistema florestal tropical (BARLOW e PERES, 2003). O fogo se apresenta como um dos principais agentes na dinâmica dos processos ecológicos, configurando-se como um importante ator do passado, presente e futuro do comportamento do sistema terrestre (BOWMAN et al., 2009). No inventário de emissões e remoções antrópicas de gases de "Efeito Estufa" não controlados pelo Protocolo de Montreal, o Brasil apontou as queimadas, juntamente com o desmatamento, como responsáveis pela maior parte dessas emissões, sendo estas provindas da Amazônia e do Cerrado (MCT, 2004).

A ação do fogo representa uma importante fatia dos danos gerados aos ecossistemas florestais nas regiões com pressão antrópica, devido a busca por novas áreas para as atividades agropecuárias por promoverem, muitas das vezes, atividades de corte raso e limpeza da área, quer seja por ocasião das queimadas como prática de manejo agropastoril, ou por descontrole, gerando incêndios florestais e originando fogo fora de controle em qualquer tipo de vegetação. Segundo Batista (2004), a pressão que essas áreas florestais sofrem têm aumentado consideravelmente o número de incêndios e a extensão das áreas queimadas.

Segundo Herawati e Santoso (2011), os incêndios florestais geram problemas em diversas escalas. Em escala local, promovem a degradação da vegetação (bens e serviços), impactos sobre a biodiversidade, prejuízos financeiros e até mesmo perda de vidas. Já em escala regional, entre outros, sua fumaça gera problemas para a saúde humana e afeta os meios de transporte. E por fim, em escala global, promovem aumento nas emissões de carbono para a atmosfera, podendo ter consequências para o clima planetário. Mesmo assim, os efeitos desse fenômeno ao ambiente ainda não têm tido atenção devida (COCHRANE, 2009).

O Painel Intergovernamental sobre Mudanças Climáticas (Intergovernmental Panel on Climate Change - IPCC), menciona que o excesso de gases de efeito estufa na atmosfera associado à redução da vegetação podem elevar a temperatura nas porções sul e leste da Amazônia, que ficariam mais suscetíveis ao fogo. Os períodos de secas severas, normalmente associados aos eventos El Niño, e a extração de madeira aumentam a inflamabilidade de grandes áreas de floresta (NEPSTAD et al., 1999), principalmente quando se considera que estas estariam mais suscetíveis ao fogo à medida que desenvolvem estoques de materiais e secos, e também estão sujeitas a uma maior temperatura em seu interior, favorecendo assim o quadro de combustão. 
Sendo assim, o comportamento climático para níveis extremados ou anômalos pode provê o ambiente favorável à ignição e desenvolvimento do fogo e, presumidamente, intensificar as ações de ocupação e ou degradação no território amazônico. No $28^{\circ}$ Relatório Anual do Estado do Clima (BLUNDEN et al., 2018), há um destaque para alguns problemas preocupantes. Dentre estes, aponta que o ano de 2017 marca o fim de uma série de novos recordes de temperatura ocorridos desde 2014, sendo o ano de 2016 o de maior registro de temperatura, seguido de 2015 e, por fim, o ano de 2017 com o terceiro ano mais quente já registrado. Desde 1997 são verificados os 10 anos mais quentes, mas a preocupação real é a taxa de aquecimento recente (NOAA, 2018). Grande parte da América do Sul registrou temperaturas acima do normal em 2017, com anomalias perto ou superior $\mathrm{a}+1^{\circ} \mathrm{C}$. A Precipitação também foi maior do que a média de 1981-2010 na maioria das áreas. O ano quente e úmido em todas as partes do norte da América do Sul pode ser atribuída em parte ao aquecimento do mar, dada as temperaturas superficiais no Pacífico equatorial oriental durante os primeiros meses de 2017.

Ao analisar os dados históricos do Instituto Nacional de Pesquisa Espaciais (INPE), percebe-se uma elevação dos patamares de focos de calor nos anos de 2015 e 2017 nos registros da Amazônia Legal. Na verdade, os registros na Amazônia Legal modelam os dados do país, já que representam cerca de $67 \%$ (média dos valores por ano) do total de valores nacionais (INPE, 2018a). Assim sendo, torna-se mister considerar que o método vicioso exploratório e contínuo de queima implantado na Amazônia traz consigo vieses de consequências silenciosas que são estabelecidas em escala local e global. Segundo Abdala (2015), este tipo de avaliação tem sido desenvolvido em perspectivas ecológicas e ambientais sistêmicas para conceber fundamentos motivadores para um tratamento especial para a maior floresta tropical do planeta.

O ambiente investigado aqui é uma parte da Amazônia de extrema importância geográfica, circunscrita em um delineamento ambiental baseado em grandes concentrações de espécies em distribuição restrita (WALLACE, 1852; SILVA DIAS et al., 2002; SILVA et al., 2005), denominado "Área de Endemismo Belém". Para Silva (2011), as áreas de endemismo são representações geográficas de distribuições de espécies e hipóteses de eventos comuns de restrição para parte de uma biota. Assim sendo, existe uma gama de processos históricos que podem causar esta restrição como, por exemplo, eventos orogenéticos, flutuações climáticas, mudanças na fisionomia vegetal ou o surgimento de barreiras geográficas.

No senso estrito, são pelo menos oito áreas de endemismo na Amazônia: Belém, Xingu, Tapajós, Rondônia, Inambari, Napo, Imeri e Guiana. Segundo Silva et al., 2005, as áreas de endemismo da Amazônia perderam de 2\% a 13\% de suas florestas. Dentre estas, a Xingu perdeu cerca de $27 \%$ de suas florestas e área de endemismo Belém tem somente cerca de um terço de sua área coberta por florestas, além de conter menos que $20 \%$ de áreas protegidas de suas terras do que as áreas de Napo, Imeri e Guiana, com 40\%, e Inambari, Rondônia, Tapajós e Xingu, entre $20 \%$ e $40 \%$. Para os autores, as áreas de endemismo deveriam ser consideradas como unidades geográficas básicas, visando o planejamento e a implementação de corredores de biodiversidade por meio de áreas protegidas contíguas, de maneira a promover ampla conectividade em seu território, assim como nas bordas destas, principalmente por abrigarem conjuntos de espécies únicas e insubstituíveis.

As áreas de endemismo, apesar de sua importância para a regionalização biogeográfica e para as estratégias de conservação, têm sido pouco estudadas, revelando a necessidade de estudos futuros de perfil interdisciplinar na Biogeografia (SILVA, 2011).

A insegurança e ameça a essas áreas têm sido pertinentes e demonstradas pela perda de habitat, a degradação e a fragmentação causada pelo desmatamento e extração seletiva de madeira (GASCON et al., 2001). De maneira geral a intensidade de uso da terra e de desflorestamento não está homogeneamente distribuída entre estas áreas, sendo o área de Endemismo Belém a mais ameaçada, dada a ocupação mais antiga das frentes pioneiras (SILVA et al, 2005).

Fundamentado neste cenário, este trabalho teve por objetivo identificar, nos últimos 20 anos, o comportamento das ações de fogo na menor Área de Endemismo Belém (SILVA et al., 2005) por meio do emprego dos dados de focos de calor. O objetivo foi conhecer a dimensão espacial e temporal da ação do fogo, de forma a contribuir para o entendimento do potencial de 
vulnerabilidade degradacional aos remanescentes florestais desse território. Dessa maneira, corroborar com ações científicas e políticas voltadas para a redução de uso do fogo como mecanismo de expansão e prática agropastoril. Os dados foram trabalhados dentro de um cenário de análise espacial por meio de técnicas de geoprocessamento.

\section{MATERIAL E MÉTODOS}

\section{ÁREA DE ESTUDO}

A Área de Endemismo Belém (Figura 1) está localizada na zona fisiográfica do leste do Pará e oeste do Maranhão, entre as coordenadas geográficas $00^{\circ} 30^{\prime} 00^{\prime \prime} \mathrm{S}$ e $06^{\circ} 00^{\prime} 00^{\prime \prime} \mathrm{S}$, e $44^{\prime}$ ' $00^{\prime}$ $00^{\prime \prime} \mathrm{O}$ e $50^{\circ} 00^{\prime} 00^{\prime \prime} \mathrm{O}$. O território analisado possui aproximadamente $243.750 \mathrm{~km}^{2}$ de área, contemplando 32 unidades de conservação (MMA, 2018a), 20 terras indígenas (FUNAl, 2018) e 168 municípios (73 no Estado do Pará e 95 no Maranhão) (IBGE, 2018).

Figura 1 - Localização da Área de Endemismo Belém.

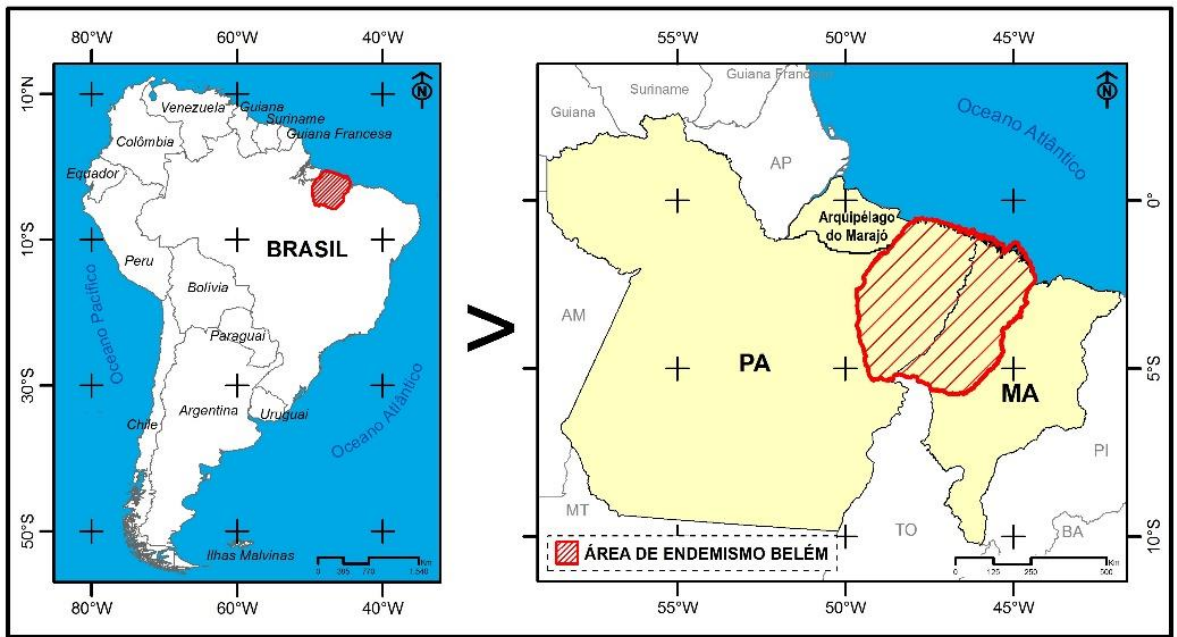

Fonte - Dados cartográficos digitais (IBGE, 2018; SILVA et al. 2005 - ajustado por ALMEIDA et al., 2013).

Os limites territoriais da área de estudo (Figura 3) são dados pelo oceano Atlântico (a norte); rio Grajaú/MA (a leste); e pelo rio Tocantins/PA (a sul e oeste), perfazendo uma zona climática $A$ (tropical chuvoso), segundo a classificação de Koppen, com cotas altimétricas entre 200 e $300 \mathrm{~m}$, cuja formação sedimentar está representada pelas Formações Barreiras e Itapecuru (ALMEIDA e VIEIRA, 2010).

Segundo João (2013), os domínios geomorfológicos do estado do Pará envolvidos pela Área Endemismo Belém correspondem a: Planície Costeira, Planície Amazônica, Tabuleiros da Zona Bragantina, Superfície do Rio Gurupi, Baixos Platôs da Bacia do Parnaíba e Depressão do Baixo Tocantins-Araguaia. Já no estado do Maranhão, constata-se: Litoral das Reentrâncias Maranhenses, Golfão e Baixada Maranhense, Superfície Sublitorânea de Bacabal, Superfícies Aplainadas do Noroeste do Maranhão, Tabuleiros de São Luís e Alcântara-Guimarães, Depressão do Médio Vale do Rio Tocantins e Planalto Dissecado Gurupi-Grajaú (BANDEIRA, 2013).

As classes de solos predominantes na área, segundo o IBGE (2008; 2011), são: Latossolo Amarelo distrófico, Plintossolo Argilúvico distrófico e Argissolo Vermelho-Amarelo distrófico. E, em menor amplitude, encontram-se: Latossolo Vermelho-Amarelo distrófico, Plintossolo Pétrico Concrecionário, Luvissolo Háplico e Gleissolos. 
A composição da cobertura vegetal e uso da terra está distribuída em: Áreas Antropizadas (floresta degradada, floresta sucessional inicial e avançada, solo exposto, agropecuária, floresta sucessional com palmeira e reflorestamento); Florestas primárias (floresta ombrófila densa e aberta); Formações pioneiras (mangue, restinga e comunidades aluviais); e Formações naturais (palmeiras, campinarana e savana) (ALMEIDA et al., 2013).

\section{Cartografia Digital}

Este trabalho utilizou como cartografia digital as bases de dados provenientes do Instituto Brasileiro de Geografia e Estatística (IBGE), Fundação Nacional do Índio (FUNAI), Ministério do Meio Ambiente (MMA) e de Silva et al. (2005), ajustado por Almeida et al. (2013). Estes dados, juntamente com os demais descritos a seguir, foram trabalhados no ambiente do software ArcGIS, versão 10.0 (ESRI, 2010).

\section{FOCOS DE CALOR}

Os dados (período de 1998 a 2017) referentes aos focos de queimadas e incêndios florestais sobre a Área de Endemismo Belém foram obtidos a partir do Banco de Dados de Queimadas (INPE, 2018a). Este banco de dados, lançado em 01/09/2016, é interativo e contem detecções dos focos de calor a partir de imagens de satélites, com atualização a cada três horas.

Segundo o INPE (2018b), os focos de calor são indicativos de que uma frente de fogo com cerca de $30 \mathrm{~m}$ de extensão por $1 \mathrm{~m}$ de largura, ou maior, será detectada. Considerando satélites com resolução espacial (pixel) de $1 \mathrm{~km} \times 1 \mathrm{~km}$, uma queimada de algumas dezenas de $\mathrm{m}^{2}$ seria identificada como tendo pelo menos $1 \mathrm{~km}^{2}$.

Sobre estes dados foram aplicadas técnicas para análise da densidade das ocorrências. Para a obtenção da densidade dos focos foi utilizada a ferramenta Densidade de Kernel presente no ArcGIS 10.0. Este método promove a observação de uma concentração de eventos finita, indicando formas de aglomeração em uma distribuição espacial - que é uma função de densidade de probabilidade de uma variável aleatória - através de zonas com gradações de intensidades por meio de cores, sendo a cor mais quente a de maior densidade.

O resultado final da soma acumulada é a densidade da Função de Kernel por $\mathrm{km}^{2}$. Os valores foram expressos dentro de uma grade de $500 \times 500 \mathrm{~m}$, de modo que o resultado final representa a densidade por $0,88 \mathrm{~km}^{2}$ de área.

Para suavização e melhor visualização dos resultados das densidades foi utilizado uma ferramenta de interpolação bilinear (para dados contínuos).

\section{Prodes e TerraClass}

Com o intuito de obter parâmetros quanto ao monitoramento na Área de Endemismo Belém, resolveu-se comparar os resultados obtidos neste trabalho aos demais obtidos por àqueles que expressam os valores oficiais de controle e monitoramento do Bioma Amazônico. Dessa maneira, foi possível fazer uma avaliação concernente à aplicabilidade dos indicadores oficiais para, talvez, fornecerem elementos capazes de contribuírem na gestão da Área de Endemismo Belém. Para tal, lançou-se mão dos dados dos sistemas PRODES (Monitoramento da Floresta Amazônica Brasileira por Satélite) (INPE, 2018c) e TERRACLASS (Qualificação do 
Desflorestamento na Amazônia Legal Brasileira) (INPE, 2018d), os quais foram tratados em ambiente de geoprocessamento para se realizarem as análises necessárias.

O PRODES fornece a taxa anual de desmatamento da Amazônia Legal realizada por meio do mapeamento da perda de floresta primária através do mapeamento da dinâmica do desmatamento por "Corte Raso", sendo este àquele que resulta da remoção completa da cobertura florestal, em um curto intervalo de tempo, para dar lugar às áreas agrícolas, pastagens, áreas urbanas, entre outras (INPE, 2013).

Já o Projeto TERRACLASS tem por objetivo qualificar o desflorestamento na Amazônia Legal Brasileira a partir dos dados do PRODES, buscando oferecer subsídios para o melhor entendimento das formas de uso e cobertura da terra na Amazônia. Os dados gerados pelo projeto são apresentados nos anos de 2004, 2008, 2010, 2012 e 2014, e disponibilizados em classes, conforme mostra a Figura 2 (INPE, 2018d).

Figura 2 - Classes de Uso e Cobertura da Terra do TERRACLASS na Área de Endemismo Belém nos anos de 2004 (A), 2008 (B), 2010 (C), 2012 (D) e 2014 (E).
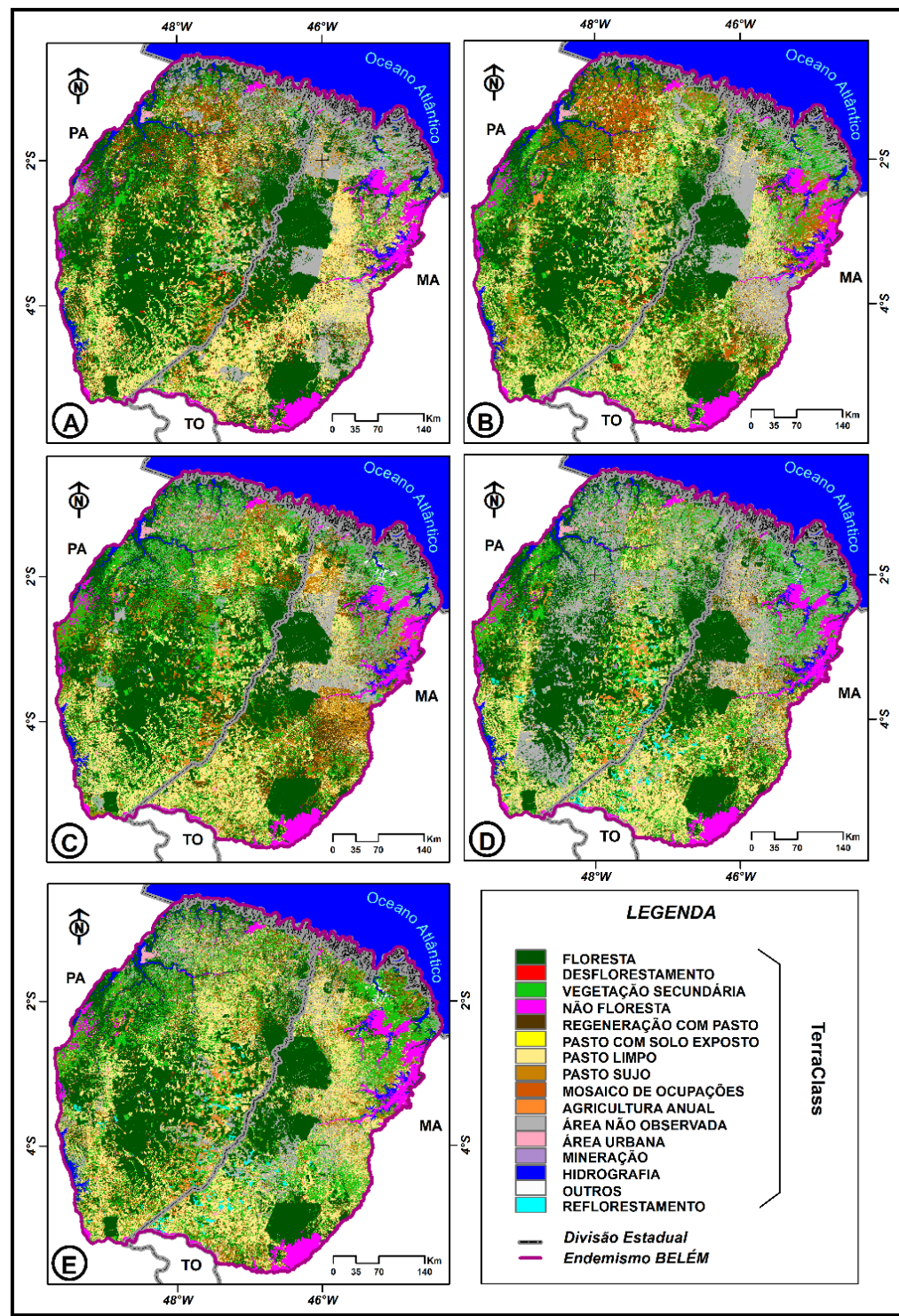

Fonte - Confeccionado pelos autores a partir de dados do TERRACLASS (INPE, 2018d). 


\section{RESULTADOS E DISCUSSÃO}

\section{AVALIAÇÃO DAS OCORRÊNCIAS dOS FOCOS DE QUEIMADAS NA ÁREA DE ENDEMISMO BELÉM}

O registro de 20 anos de ocorrência de focos de calor na Área de Endemismo Belém é demonstrado na Figura 3. É possível notar uma diminuição no quantitativo das ocorrências, a partir de 2010, abaixo da média do período estudado, cujo valor é de 17.836 focos, entre 1999 e 2017. Além disso, é notório uma ordem decrescente nos dados do PRODES até patamares mais baixos a partir de 2012. No ano de 2001, em função do grande valor acumulado e dada a ausência de imagens em anos anteriores, os valores do PRODES foram desconsiderados.

Figura 3 - Ocorrências de focos de calor (A) e desmatamento (B) na Área de Endemismo Belém.

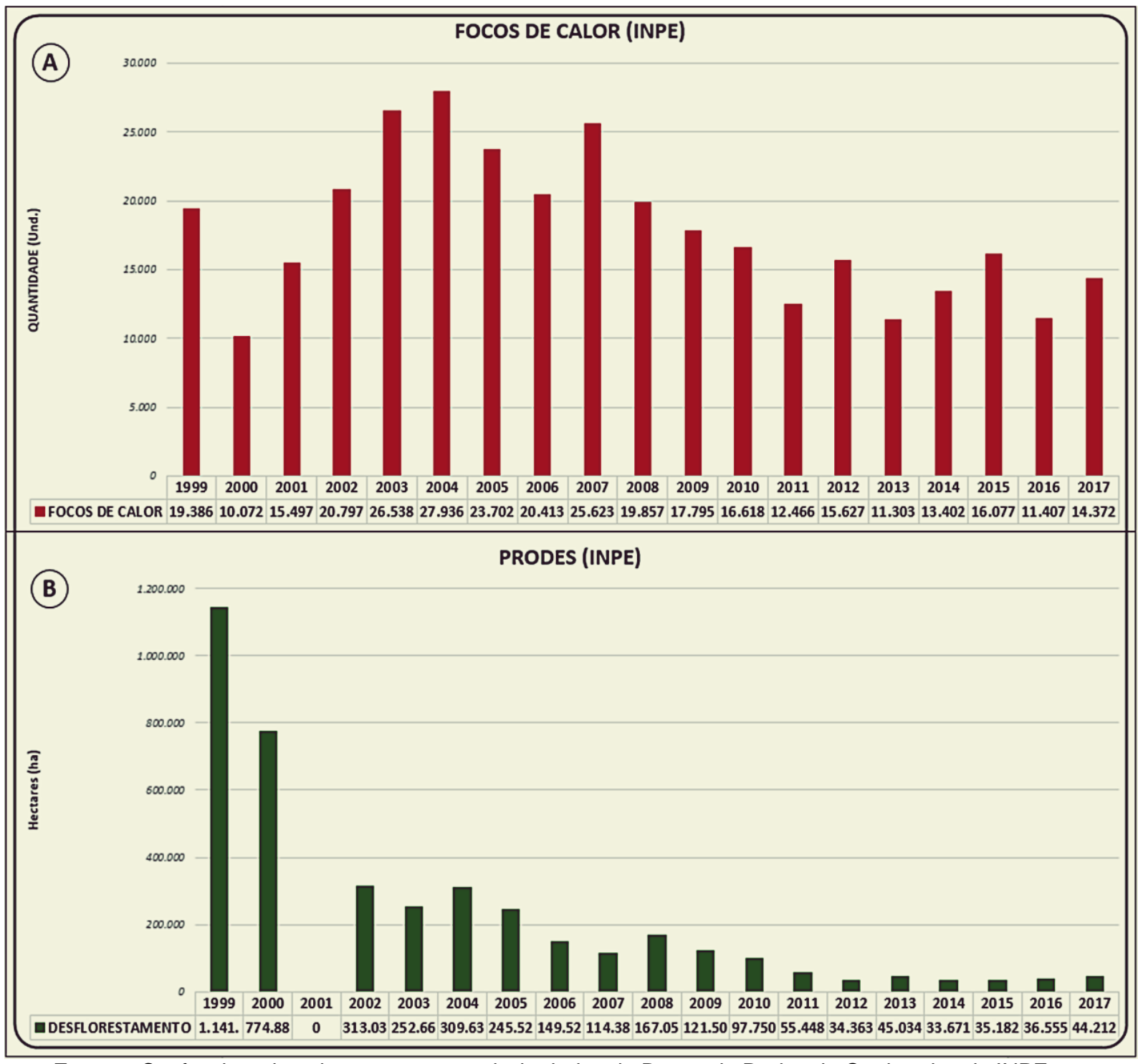

Fonte - Confeccionado pelos autores a partir de dados do Banco de Dados de Queimadas do INPE (INPE, 2018a) e PRODES (INPE, 2018c).

O comportamento dos focos de calor, de modo geral, expressam os avanços que algumas políticas de fiscalização e controle brasileiras foram importantes, à exemplo do Sistema Nacional de Prevenção e Combate aos Incêndios Florestais - PREVFOGO (Decreto n. 97.635, de 
10/04/1989 - revogado pelo Decreto n. 2.661, de 08/07/1998) e do Programa de Prevenção e Controle às Queimadas e aos Incêndios Florestais na Amazônia Legal - PROARCO (Decreto n. 2.662, de 08/07/1998 - revogado pelo Decreto n. 2.959, de $10 / 02 / 1999$ ). Mais tarde, estas ações foram somadas a um grande compromisso de mudar a realidade imposta à Amazônia brasileira por meio do Plano de Ação para Prevenção e Controle do Desmatamento na Amazônia Legal (PPCDAm).

O PPCDAm, criado em 2004, desenvolveu ações (Figura 4) para reduzir de forma contínua e consistente o desmatamento, cujo objetivo central era de estabelecer um modelo de desenvolvimento sustentável na Amazônia Legal (MMA, 2018b).

Figura 4 - Resultados do PPCDAm dentro do cenário de desmatamento da Amazônia Legal.

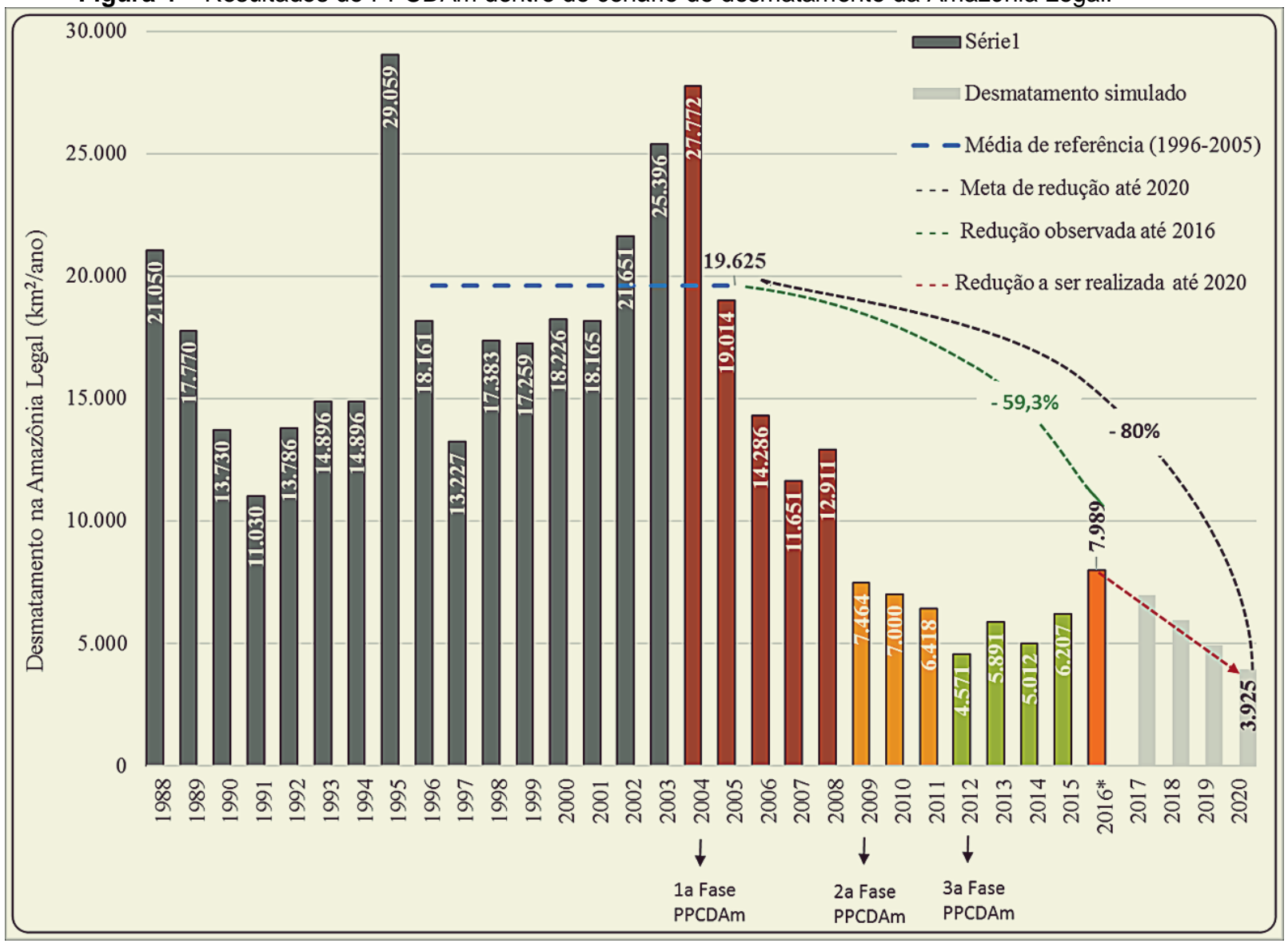

Fonte - MMA (2018b)

No entanto, os registros de focos (Figura 3A) mantêm em perspectiva o alerta para tal prática, pois há muito a se fazer. Isto é relevante à medida que os compromissos mundiais dos quais 0 Brasil pretende atingir são importantes para o quadro de redução das emissões dos gases do efeito estufa

Na Figura 5, é demonstrado o perfil espacial dos focos de calor na Área de Endemismo Belém sobre as classes de cobertura vegetal e uso da terra do Projeto TERRACLASS nas cinco datas disponíveis (2004, 2008, 2010, 2012 e 2014). As classes de maior relevância foram assim ordenadas: "Floresta”, "Vegetação Secundária", "Desflorestamento", "Pasto Limpo", "Pasto Sujo", "Mosaico de Ocupações" e "Agricultura Anual". 
Figura 5 - Ocorrência espacial dos focos de calor sobre as classes de uso e cobertura da terra do TERRACLASS, nos anos de 2004 (A), 2008 (B), 2010 (C), 2012 (D) e 2014 (E).

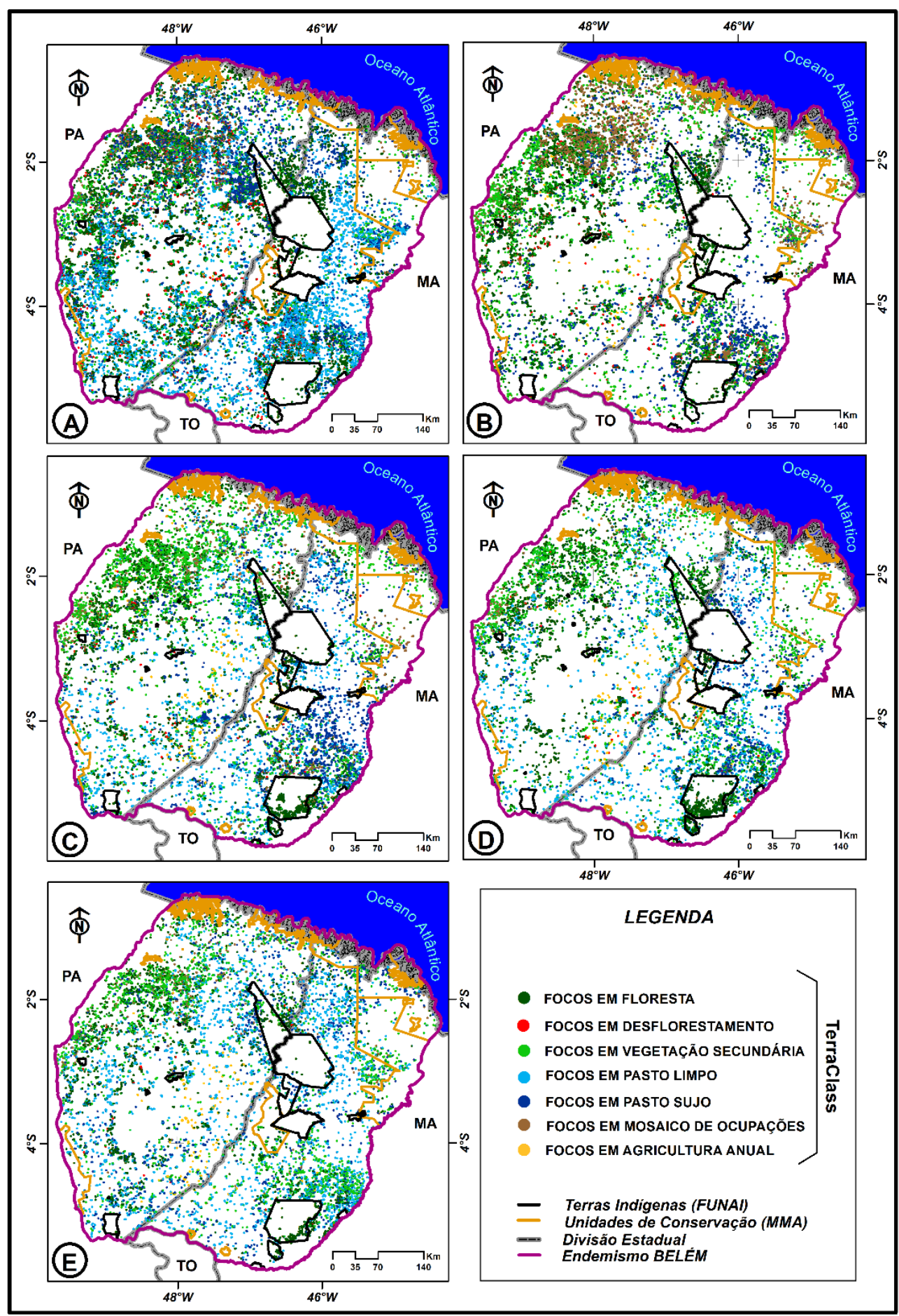

Os resultados mostram o comportamento dos registros de focos de calor em três zonas de intensidade na Área de Endemismo Belém: à Noroeste e à Sudeste (maiores densidades); e à Centro-Norte (menor densidade). É possível perceber um maior quantitativo de ocorrências de focos de calor nas classes de "Floresta", "Vegetação Secundária", "Pasto Limpo" e "Pasto Sujo", com exceção da inclusão, em 2008 (Figura 5B), das ocorrências sobre a classe "Mosaico de Ocupações". 
A partir da Figura 6, é possível traçar um entendimento mais pleno em relação a esta variabilidade de ocorrências, observando a evolução das ocorrências de focos de calor ao longo do tempo. Os valores mais relevantes foram definidos em razão de suas magnitudes (classes onde os focos foram mais frequentes). Juntos, estes valores representaram aproximadamente 95\% (88.701 de 93.440 focos no total) dos focos de calor na Área de Endemismo Belém nos anos de 2004, 2008, 2010, 2012 e 2014 do TERRACLASS (vide Figura 3A).

Figura 6 - Quantitativo espacial de focos de calor sobre as classes de uso e cobertura da terra do TERRACLASS.

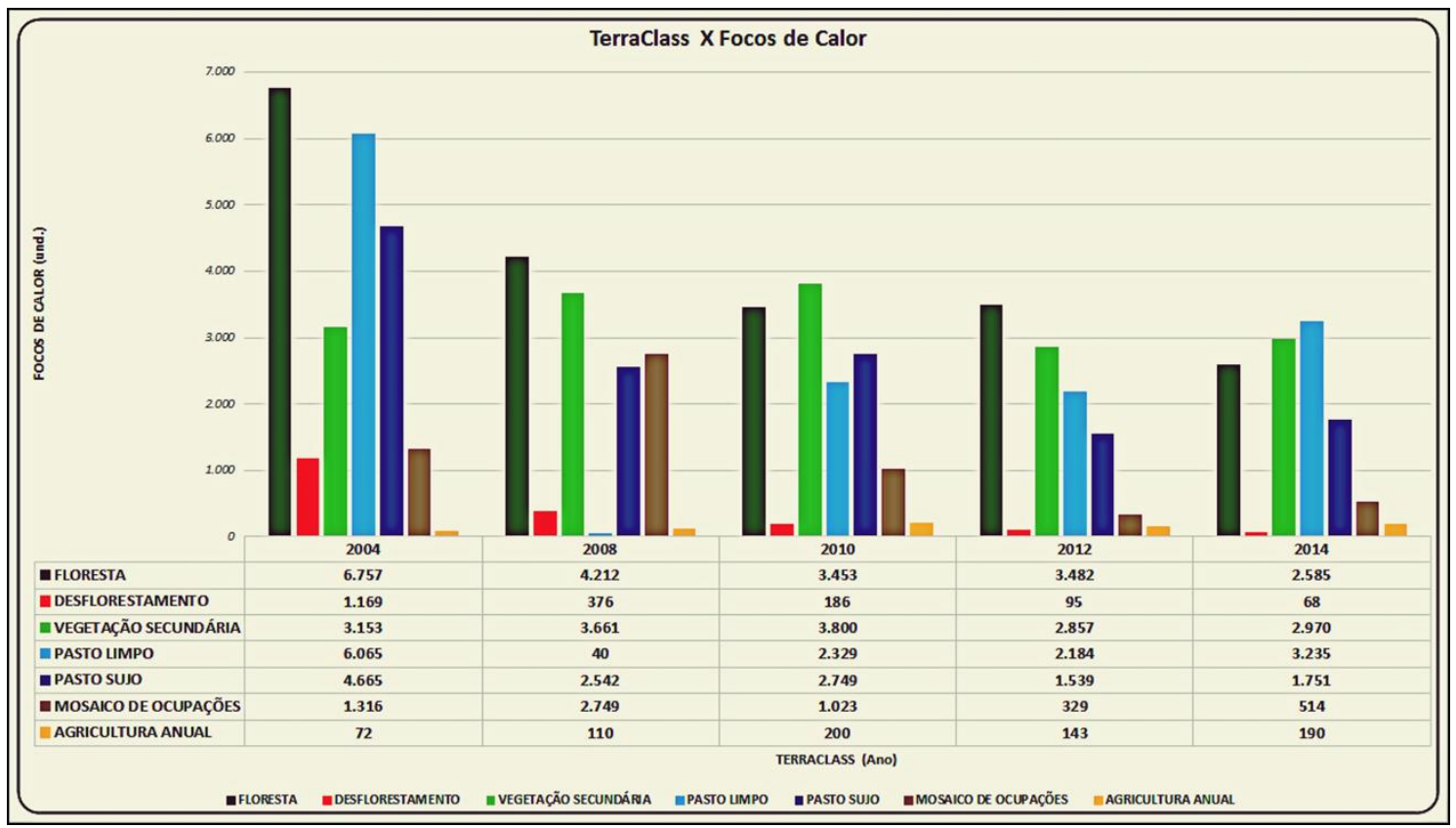

Foi possível notar um decréscimo nas ocorrências de focos de calor em "Floresta" ao longo do período analisado (na ordem de $38,2 \%$ - de 2004 a 2014), mesmo assim, seu valor acumulado foi maior na Área de Endemismo Belém (20.489 focos - 21,9\% do total dos focos em todas as datas). Uma grande dimensão de ocorrências pôde ser observada em áreas de "Vegetação Secundária" com o segundo maior valor, 16.441 focos $(17,6 \%$ do total dos focos em todas as datas); seguido dos valores de ocorrência em Pasto Limpo (13.853 focos - 14,8\% do total dos focos em todas as datas) e Pasto Sujo (13.246 focos - 14,2\% do total dos focos em todas as datas). Se forem somados os valores de ocorrência de focos de calor nas classes de pasto, terse-á 27.099 focos de calor ( $29 \%$ do total dos focos em todas as datas) ocorridos nessas áreas, ultrapassando os quantitativos de "Floresta" e "Vegetação Secundária".

Esta avaliação deixa claro que, representando $70 \%$ dos registros totais em mais de uma década, os focos de calor concentraram-se em zonas onde há um indicativo claro da participação das práticas tradicionais de manejo, mesmo com a diminuição do desmatamento (Figura 3B).

Além das qualificações de ocorrências dos focos de calor, é possível notar uma certa quantidade de ocorrências dentro de terras indígenas e unidades de conservação (Figura 5). Nas terras indígenas a qualificação se dá em áreas de floresta, bastante pronunciadas em 2010 (Figura 5C), 2012 (Figura 5D) e 2014 (Figura 5E). Já nas unidades de conservação, é possível notar a ocorrência constante, em todos os anos, nas classes de "Vegetação Secundária", "Pasto Limpo" e "Pasto Sujo".

Afora os focos de calor detectados no interior destas áreas, as pressões de implementação do fogo são bem caracterizadas em áreas vizinhas a elas. Isto demonstra uma presença antrópica bem ativa e constante nestes cenários, além de oportunamente representarem riscos a biodiversidade destes remanescentes florestais por meio de ações de degradação silenciosa e constante, resultando em um comportamento recorrente de degradação e uso. Por isto, foi realizada uma análise para estabelecer espacialmente quais as áreas mais afetadas pela 
ocorrência de focos de calor e, a partir disso, poder indicar as áreas vulneráveis à degradação potencial pelo fogo.

Dessa maneira, a partir da dinâmica de ocorrências de focos de calor ao longo de 20 anos (Figura 3A) foi possível apontar os locais de grande recorrência na Área de Endemismo Belém (Figura 7).

Figura 7- Densidade Kernel (B) gerada a partir do acumulado de focos de calor em 20 anos (A).

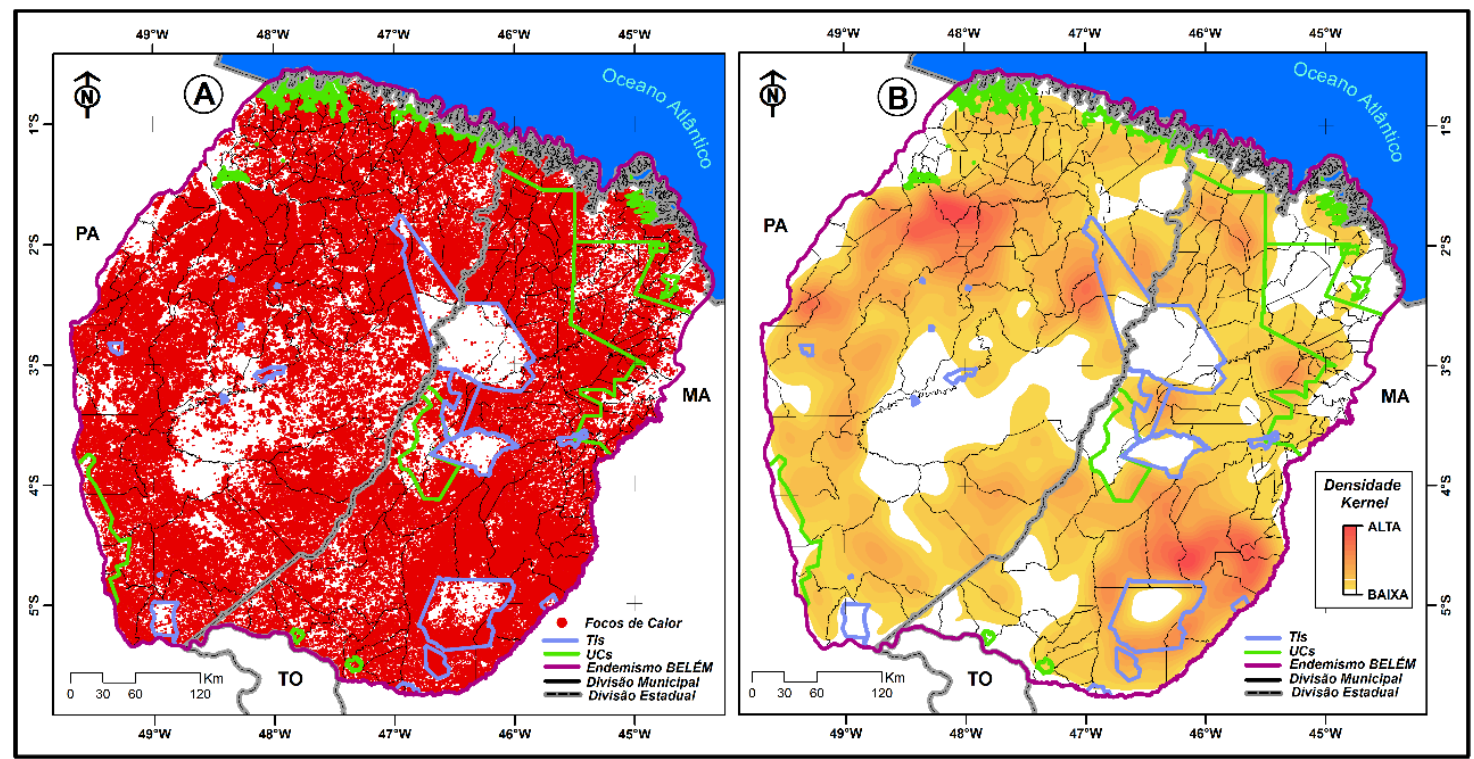

Apesar da grande intensidade dos focos de calor em toda área, foi possível determinar as zonas com maior intensidade de ocorrências. Na Figura 7, é possível visualizar as zonas de maior intensidade e, portanto, de maior potencial de vulnerabilidade à degradação por meio do fogo na Área de Endemismo Belém, demonstrando inclusive um perfil de recorrência à riscos de incêndios.

Os locais da disposição espacial de alta "Densidade Kernel" de ocorrência de focos de calor na Área de Endemismo Belém são: municípios à Noroeste da área (sudeste do Acará/PA, sul de Bujaru/PA, extremo leste de Cametá/PA, norte de Concórdia do Pará/PA, extremo sul de IgarapéMiri/PA e extremo centro-oeste de Moju/PA); municípios à Centro-Norte da área (norte de Mocajuba/PA, parte central de Nova Esperança do Piriá/PA e oeste de São Domingos do Capim/PA); e, por fim, municípios à Sudeste da área (nordeste e sudoeste de Arame/MA, sul de Brejo de Areia/MA, oeste de Buriticupu/MA, parte central de Marajá do Sena/MA, leste de Paulo Ramos/MA e sul de Santa Luzia/MA).

A partir desse entendimento, foi possível estruturar um mapa para expressar a dimensão deste impacto de recorrências ao longo de 20 anos e definir as influências espaciais destes extremos sobre a Área de Endemismo Belém. Na Figura 8 as Terras Indígenas (TI) e Unidades de Conservação (UCs) são enumeradas da seguinte maneira: 1 - TI Araribóia/MA; 2 - TI Governador/MA; 3 -TI Geralda Toco Preto/MA; 4 - TI Caru/MA; 5 - TI Awa/MA; 6 - TI Alto Turiaçu/MA; 7 - TI Alto Rio Guamá/PA; 8 - Reserva Biológica do Gurupi/MA; e 9 - Área de Proteção Ambiental da Baixada Maranhense/MA.

Os resultados expressos no mapa de Zonas de recorrência (Figura 8) demonstram dois importantes cenários de vulnerabilidade da ação do fogo, a saber: as Tls 1, 2, 3, 4, 5, 6 e 7; e as UCs 8 e 9 
Neste cenário de intensa recorrência espacial ao longo de 20 anos, ganha destaque àquelas que englobam remanescentes florestais, pois representam ambientes biodiversos importantes dentro da Área de Endemismo Belém, sendo as mais afetadas pela recorrência as Tls 1, 2, 3, 5 e 7.

Figura 8 - Zonas de recorrência de focos de calor (20 anos).

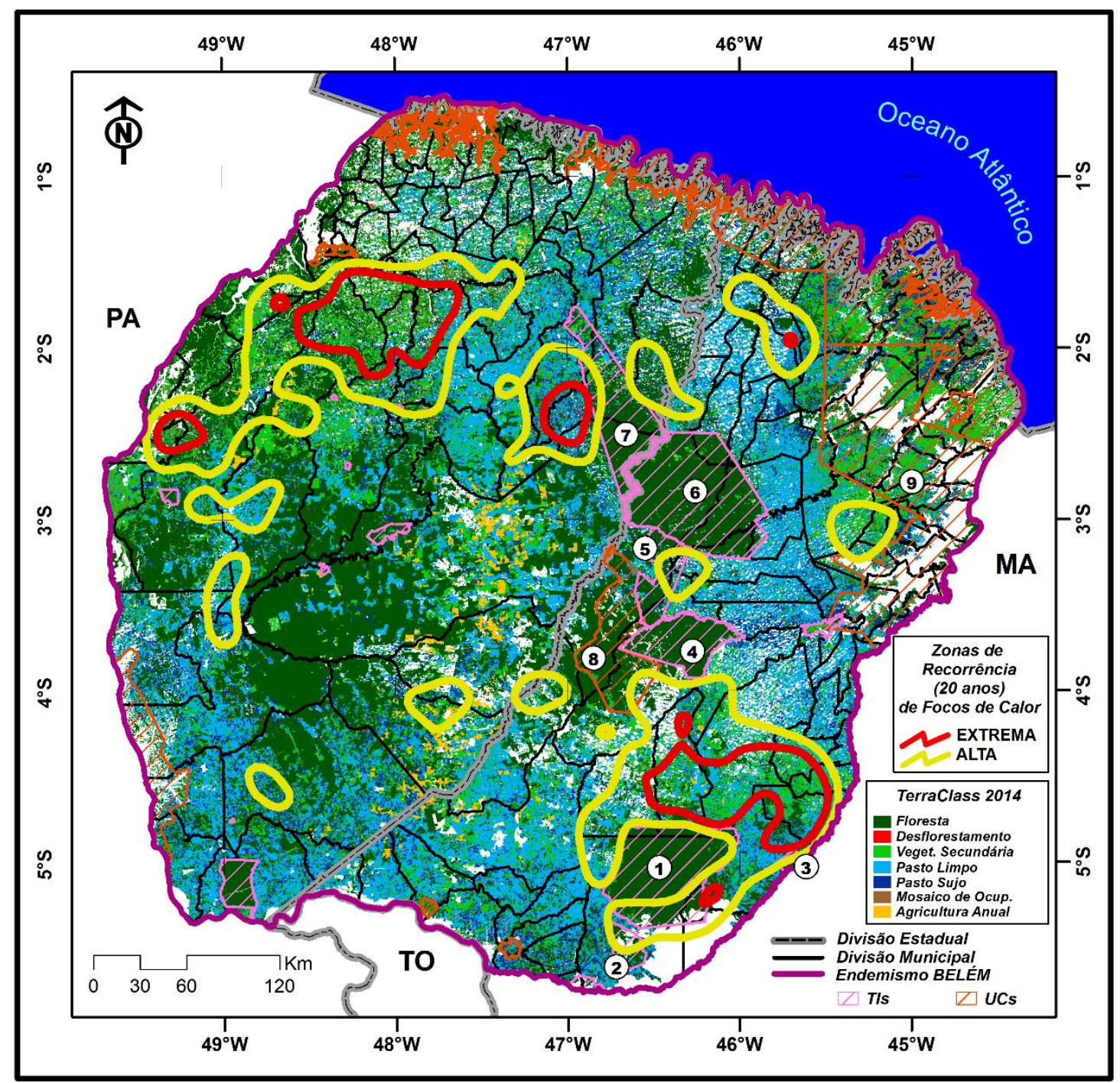

Os resultados espaciais das recorrências de focos de calor na Área de Endemismo Belém salientam o amplo processo cultural implícito de expansão ocupacional de novas áreas para as atividades agropecuárias (corte raso) ou como técnica agrícola utilizada no manejo agropastoril (limpeza da área). Esta tem sido a tônica das atividades de produção reinantes e amplamente utilizada e discutida ao longo do tempo e que precisam encontrar uma dimensão mais adequada à realidade de um desenvolvimento aceitável globalmente do ponto de vista sócio-econômicoambiental, tendo em vista os compromissos signatários que o Brasil dispõe.

Este modelo se sustenta devido, em grande parte, às deficiências na conversão efetiva das ações de governança do território ao setor primário, cujos objetivos seriam de quebra de paradigmas visando uma evolução do quadro de maneira progressiva e eficiente. Este quadro é possível ser percebido à medida que avaliamos as evidências expressas em dados estatísticos da realidade do campo.

Na Figura 9, é apresentado uma análise espacial gerada pela sobreposição dos resultados de recorrência de focos de calor da Área de Endemismo Belém aos dados de Índice de 
Desenvolvimento Rural (IDR) sintético para microrregiões brasileiras. Para expressar o caráter multidimensional do desenvolvimento rural, este indicador foi gerado a partir de estatística multivariada (análise fatorial-método componentes principais) para compreender as desigualdades regionais do desenvolvimento rural em nosso país (STEGE e PARRÉ, 2013).

Figura 9 - Zonas de recorrência de focos de calor (20 anos) sobre indicativos de desenvolvimento rural de microrregiões na Área de Endemismo Belém.

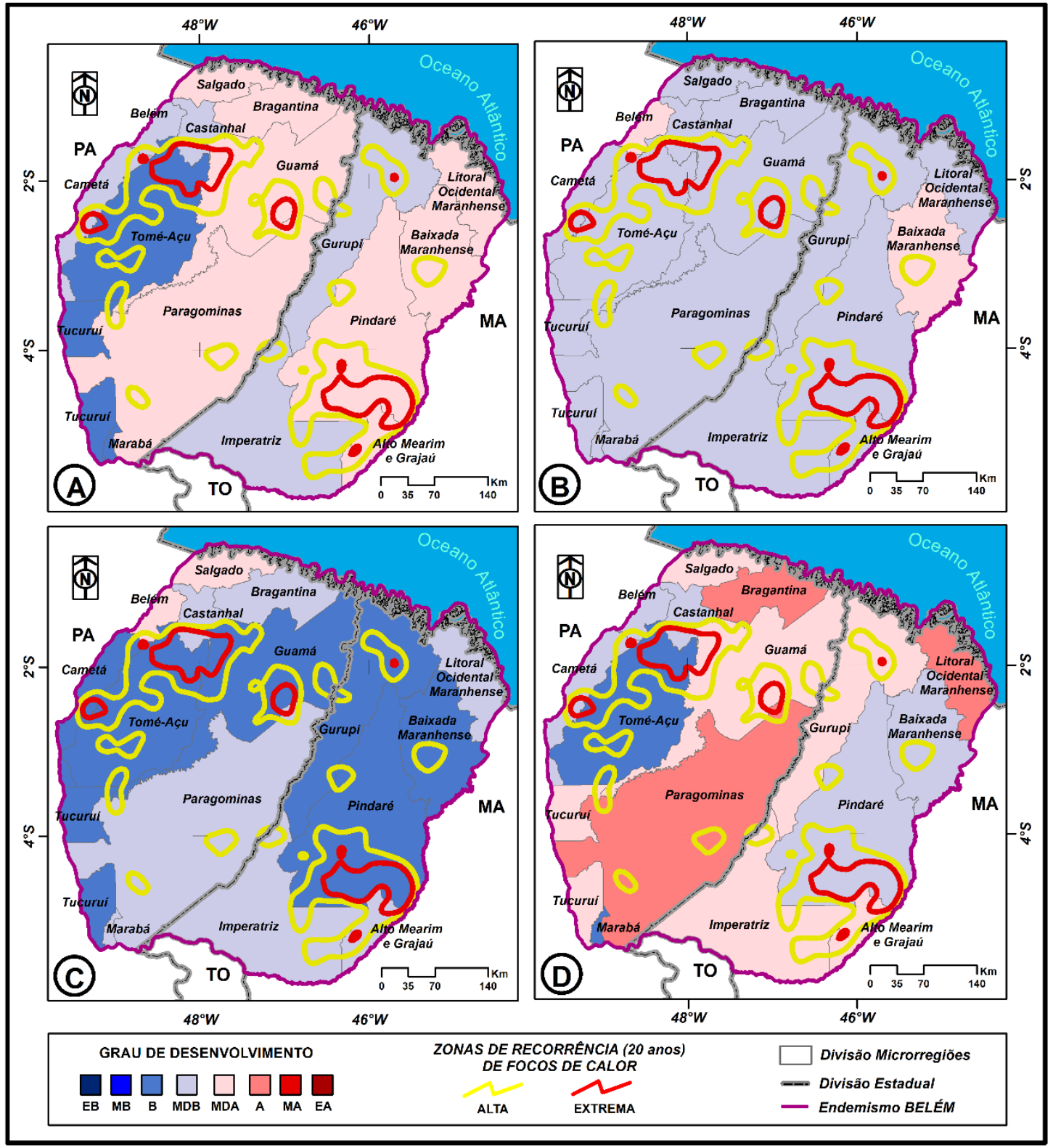

Fonte - Confeccionado a partir de dados do IBGE (2018), Stege e Parré (2013) e resultados da pesquisa.

A Figura 9 demonstra quatro cenários. O primeiro, expressa os valores do IDR (Figura 9A). O segundo, terceiro e quarto (Figuras 9B, 9C e 9D, respectivamente), representam os escores fatoriais (Fatores 1: produtividade dos fatores de produção e a renda agrícola da microrregião; Fator 2: qualidade de vida nos domicílios rurais; e Fator 3: preservação ambiental) que expressaram cerca de $40 \%$ da variância acumulada na construção do status de desenvolvimento rural nas microrregiões do país, segundo Stege e Parré (2013). 
Ao se analisar o conjunto de dados espaciais, foi possível atribuir que as principais zonas de recorrência de focos de calor ao longo de 20 anos estão situadas em áreas definidas em um grau de desenvolvimento rural bem abaixo da média nacional (STEGE e PARRÉ, 2013).

$\mathrm{Na}$ Figura 9A, as zonas à Noroeste da Área de Endemismo Belém, encontram-se situadas, na maior parte, em áreas de IDR Médio Baixo (MDB) a Baixo (B), enquanto às situadas à CentroNorte e à Sudeste, estão em áreas de IDR Médio Alto (MDA). Essa pequena variação espacial das zonas de recorrência de focos de calor em relação às classes do IDR, pode estar relacionada a variáveis municipais que elevaram os resultados (escores fatoriais) de municípios à Sul da microrregião de Pindaré/MA, tendo em vista que guardam uma certa coerência espacial em relação as demais classes fatoriais (Figura 9B, 9C e 9D) existentes. De maneira que, esperavase que as mesmas estivessem sobre classes de grau de desenvolvimento Médio Baixo (MDB) a Baixo (B).

De qualquer forma, ganha destaque a análise da Figura 9D, cujo teor diz respeito a preservação ambiental. Conforme Stege e Parré (2013), com exceção das microrregiões Bragantina/PA, Paragominas/PA e Litoral Ocidental Maranhense/MA, as zonas de recorrência de focos de calor mais importantes se encontram sobre classes de grau de desenvolvimento abaixo da média nacional, o que thes confere um cenário de problemas ambientais de contaminação de solo e desmatamento.

De modo geral, o esboço destas análises traz um sentido pleno de que tipicamente está se falando de territórios que ainda detém conceitos, condições e atividades produtivas, que estão pautados em práticas tradicionais de ocupação e manejo na Amazônia, mostrando a necessidade de inferências mais eficazes, principalmente quanto às ligadas ao fogo, para adequarem cenários de desenvolvimento sustentável inerentes à realidade da Área de Endemismo Belém e, por conseguinte, da Amazônia.

\section{CONSIDERAÇÕES FINAIS}

Apesar das taxas de desmatamento na Área de Endemismo Belém terem diminuído nos últimos 20 anos, os registros de focos de calor expressaram um comportamento oposto a essa tendência, indicando que não existiu uma relação direta entre o desmatamento e o fogo.

As três zonas de maior intensidade de recorrência de fogo na Área de Endemismo Belém demonstraram ser cenários vulneráveis aos seus remanescentes florestais de importante biodiversidade, a julgar, inclusive, pelas ocorrências de focos de calor dentro destas áreas.

As classes de uso e cobertura da terra onde se verificou a maior quantidade de focos de calor (nos últimos 14 anos), em ordem decrescente, foram: Floresta (21,9\%); Vegetação Secundária $(17,6 \%)$; Pasto Limpo $(14,8 \%)$ e Pasto Sujo $(14,2 \%)$. O somatório destes valores garantiu aproximadamente $70 \%$ das recorrências anuais em mais de uma década. No entanto, sem desconsiderar a importância dos valores em áreas de floresta, a maior parte dos focos de calor são originários de manejo agropastoril, quer sejam em áreas de regeneração ou em pasto.

Foi possível corroborar este fato à medida que, nestes 20 anos de práticas de fogo na Área de Endemismo Belém, as maiores densidades de recorrência dos focos de calor estiveram presentes em microrregiões onde o grau de desenvolvimento rural é bem abaixo da média nacional, ainda mais quando a variável em questão foi a preservação ambiental. Com exceção das microrregiões Bragantina/PA, Paragominas/PA e Litoral Ocidental Maranhense/MA, as demais zonas de recorrência de focos de calor se encontram em microrregiões onde esta variável ambiental está abaixo da média nacional, indicando tipicamente problemas ligados a contaminação do solo e ao desmatamento.

Estes resultados demonstram a necessidade de ações institucionais mais concentradas a essa temática do fogo para que o desenvolvimento sustentável alcance um modelo adequado à realidade da área e, por conseguinte, seus efeitos sejam positivos em nível regional e global. 


\section{AGRADECIMENTOS}

Ao Conselho Nacional de Desenvolvimento Científico e Tecnológico (CNPq), pela concessão de Bolsa de Desenvolvimento do Programa de Capacitação Institucional PCI/MCTIC.

Ao Museu Paraense Emílio Goeldi (MPEG)/Coordenação de Ciências da Terra e Ecologia (COCTE)/Unidade de Análises Espaciais (UAS), pela oportunidade da pesquisa e infraestrutura para o desenvolvimento deste trabalho.

\section{REFERÊNCIAS BIBLIOGRÁFICAS}

ABDALA, G. C. Amazônia Brasileira: desafios para uma efetiva política de combate ao desmatamento. Brasília, WWF Iniciativa Amazônia Viva e WWF Brasil, 1를 ed. 2015. 68 p.

ALMEIDA, A.S.; VIEIRA, I. C. G. Centro de Endemismo Belém: status da vegetação remanescente e desafios para a conservação da biodiversidade e restauração ecológica. REU, Sorocaba, SP, v. 36, n. 3, p. 95-111. 2010.

ALMEIDA, A. S.; VIEIRA, I. C. G.; ROCHA, D. P. N. Cenários para a Amazônia: clima, biodiversidade e uso da terra. Caracterização e mapeamento dos padrões de uso da terra na Área de Endemismo Belém. Boletim do Museu Paraense Emílio Goeldi, p. 170, 2013.

BANDEIRA, I. C. N. Geodiversidade do estado do Maranhão/Organização Iris Celeste Nascimento. Teresina: CPRM, 2013. 294 p.: il. 30cm + 1 DVD-ROM.

BARLOW, J; PERES, C. A. Fogo rasteiro: nova ameaça na Amazônia. Ciência Hoje, v. 34, n.199, p: 24-29, 2003.

BATISTA, A. C. Detecção de incêndios florestais por satélites. Floresta, v. 34, n. 2, p. 237-241, 2004.

<http://queimadas.cptec.inpe.br/ rqueimadas/material3os/2004_Batista_Deteccao_Floresta_DE 3os.pdf>. Acesso em: 20 nov. 2018. https://doi.org/10.5380/rf.v34i2.2402

BOWMAN, D. M. J. S.; BALCH, J. K.; ARTAXO, P.; BOND, W. J.; CARLSON, J. M.; COCHRANE, M. A.; ANTONIO, C. M. D.; DEFRIES, R. S.; DOYLE, J. C.; HARRISON, S. P.; JOHNSTON, F. H.; KEELEY, J. E.; KRAWCHUK, M. A.; KULL, C. A.; MARSTON, J. B.; MORITZ, M. A.; PRENTICE, I. C.; ROOS, C. I.; SCOTT, A. C.; SWETNAM, T. W.; VAN DER WERF, G. R.; PYNE, S. J. Fire in the Earth System. Science, v. 324, n. 5926, p. 481-484, 2009. https://doi.org/10.1126/science.1163886

BLUNDEN, J.; ARNDT, D. S.; HARTIFIELD, G., Eds., 2018: State of the Climate in 2017. Bull. Amer. Meteor. Soc., 99 (8), Si-S310, doi:10.1175/2018BAMSStateoftheClimate.1. https://doi.org/10.1175/2018BAMSStateoftheClimate.1

COCHRANE, M. A. Tropical fire ecology: climate change, land use, and ecosystem dynamics. Chichester: Springer-Praxis, 2009. https://doi.org/10.1007/978-3-540-77381-8

ESRI - ENVIRONMENTAL SYSTEMS RESEARCH INSTITUTE. ArcGIS Professional GIS for the desktop, versão 10.0, 2010.

FERREIRA, J.; BLANC, L.; KANASHIRO, M.; LEES, A. C.; BOURGOIN, C.; FREITAS, J. V. de; GAMA, M. B.; LAURENT, F.; MARTINS, M. B.; MOURA, N.; OLIVEIRA, M. V. N. d'; SOTTA, E. D.; SOUZA, C. R. de; RUSCHEL, A. R.; SCHWARTZ, G.; ZWERTS, J.; SIST, P. Degradação florestal na Amazônia: como ultrapassar os limites conceituais, científicos e técnicos para mudar esse cenário. Belém, PA: Embrapa Amazônia Oriental, 2015. 29 Pág. (Documentos/Embrapa Amazônia Oriental, ISSN 1983-0513; 413). Disponível em: $<$ https://agritrop.cirad.fr/584420/1/DOC413.pdf>. Acesso em: 20 jan. 2019.

FUNDAÇÃO NACIONAL DO ÍNDIO. 2018. Shape. Disponível em: <http://www.funai.gov.br/index.php/shape >. Acesso em: 19 nov. 2018

GASCON, C., BIERREGAARD JR., R. O.; LAURANCE, W.F.; RANKIN-DE-MÉRONA, J. Deforestation and forest fragmentation in the Amazon. In: BIERREGAARD JR., R. O.; GASCON, 
C.; LOVEJOY, T. E.; MESQUITA, R. (eds.). Lessons from Amazonia: the ecology and conservation of a fragmented forest. Yale University Press, New Haven, EUA. p. 22-30, 2001.

HERAWATI, H.; SANTOSO, H. Tropical Forest Susceptibility to and Risk of Fire under Changing Climate: A Review of Fire Nature, Policy and Institutions in Indonesia. Forest Policy and Economics, v. 13, p. 227-233. 2011. https://doi.org/10.1016/.jorpol.2011.02.006

INSTITUTO BRASILEIRO DE GEOGRAFIA E ESTATÍSTICA (IBGE). 2008. Mapa Esquemático de Solos do estado do Pará. Disponível em: <https://mapas.ibge.gov.br/temáticos/solos>. Acesso em: 22 nov. 2018.

2011. Mapa Exploratório de Solos do estado do Maranhão. Disponível em: <https://mapas.ibge.gov.br/temáticos/solos>. Acesso em: 22 nov. 2018.

2018. Geociências: Cartas e Mapas (Bases cartográficas contínuas). Disponível em: <https://www.ibge.gov.br/geociencias-novoportal/cartas-e-mapas/bases-cartograficascontinuas/15759-brasil.html?edicao=16034\&t=downloads>. Acesso em: 10 out. 2018.

INSTITUTO NACIONAL DE PESQUISAS ESPACIAIS - INPE. 2013. Metodologia para o Cálculo da Taxa Anual de Desmatamento na Amazônia Legal. Disponível em: $<$ http://www.obt.inpe.br/OBT/assuntos/programas/amazonia/prodes/pdfs/metodologia_taxaprod es.pdf>. Acesso em: 20 nov. 2018.

2018a. Programa Queimadas (Dados). Disponível em: <http://www.inpe.br/queimadas/portal/estatistica_estados>. Acesso em: 10 out. 2018.

2018b. Programa Queimadas (Dados). Disponível em: <https://queimadas.dgi.inpe.br/queimadas/informacoes/perguntas-frequentes>. Acesso em: 20 nov. 2018.

2018c. Projeto PRODES Digital (Dados). Disponível em: <http://www.obt.inpe.br/prodesdigital/cadastro.php >. Acesso em: 12 out. 2018.

2018d. Projeto TERRACLASS (Dados). Disponível em: <http://www.obt.inpe.br/prodesdigital/cadastro.php >. Acesso em: 12 out. 2018.

MINISTÉRIO DA CIENCIA E TECNOLOGIA (MCT). 2004. Inventário Brasileiro de emissões antrópicas de gases de efeito estufa: comunicação inicial do Brasil. Brasília, Brasil. Disponível em: <http://www.mct.gov.br/upd_blob/0004/4199.pdf>. Acesso em: 22 jan. 2018.

MINISTÉRIO DO MEIO AMBIENTE (MMA). 2018a. Cadastro Nacional de Unidades de Conservação (CNUC). Disponível em: < http://www.mma.gov.br/areas-protegidas/cadastronacional-de-ucs>. Acesso em: 19 nov. 2018.

2018b. Plano de Ação para Preservação e Controle do Desmatamento na Amazônia Legal. Disponível em: <http://www.mma.gov.br/informma/item/616-preven\%C3\%A7\%C3\%A3oe-controle-do-desmatamento-na-amaz\%C3\%B4nia.html>. Acesso em: 26 nov. 2018.

NATIONAL OCEANIC AND ATMOSPHERIC ADMINISTRATION (NOAA). 2018. Climate at a glance: global time series. Disponível em: <https://www.ncdc.noaa.gov/cag/global/timeseries>. Acesso em: 22 nov. 2018.

NEPSTAD, D. C.; MOREIRA, A. G.; ALENCAR, A. A. A Floresta em Chamas: Origens, Impactos e Prevenção de Fogo na Amazônia. Programa Piloto para a Proteção das Florestas Tropicais do Brasil, Brasília, Brasil. 1999. 202 p.

SILVA, J. M. C.; RYLANDS, A. B.; FONSECA, G. A. B. O destino das áreas de endemismo da Amazônia. Megadiversidade, v.1, n.1, p. 124-131. 2005.

SILVA, M. B. Áreas de endemismo: as espécies vivem em qualquer lugar, onde podem ou onde historicamente evoluíram? Revista da Biologia, v. 7 (Vol. Esp. Biogeografia), p. 12-17. 2011. Disponível em: <http://www.ib.usp.br/revista/volume7>. Acesso em: 23 de março de 2017. https://doi.org/10.7594/revbio.07.03

SILVA DIAS, M. A. F.; RUTLEDGE, S.; KABAT, P.; SILVA DIAS, P. L.; NOBRE, C.; FISCH, G.; DOLMAN, A. J.; ZIPSER, E.; GARSTANG, M.; MANZI, A. O.; FUENTES, J. D.; ROCHA, H. R.; 
MARENGO J.; PLANA-FATTORI, A.; SA, L. D. A.; ALVALA, R. C. S.; ANDREAE, M. O.; ARTAXO, P.; GIELOW, R. \& GATTI, L. Cloud and rain processes in a biosphereatmosphere interaction context in the Amazon Region,. Journal of Geophysical Research., 8072-8092p. 2002. https://doi.org/10.1029/2001JD000335

STEGE, A. L.; PARRÉ, J. L. Fatores que determinam o desenvolvimento rural nas microrregiões do Brasil, Confins [Online], n. 19, 2013. DOI: 10.4000/confins.8640. Disponível em: <https://journals.openedition.org/confins/8640?lang=pt>. Acesso em: 28 nov. 2018. https://doi.org/10.4000/confins.8640

WALLACE, A. R. On the monkeys of the Amazon. Proceedings of the Zoological Society of London. v. 20, p.107-110, 1852.

Recebido em: 08/05/2019

Aceito para publicação em: 18/07/2019 